\title{
FOTO

\section{La crisis constructiva del sueño europeo en Metrópolis, de Fritz Lang. Un estudio contextual comparado de los mitos de Prometeo y Atlas}

\section{The Crisis of the European Dream in Fritz Lang's Metropolis. A comparative contextual study of the myths of Prometheus and Atlas}

\author{
Marcos Jiménez González \\ Universidad a distancia de Madrid, España \\ marcos.jimenez.g@udima.es \\ Jorge Latorre Izquierdo \\ Universidad Rey Juan Carlos, España \\ jorge.latorre@urjc.es
}

\section{Resumen:}

Metrópolis de Fritz Lang es una película de enorme complejidad que casi cien años después de su estreno sigue provocando polémica en torno a las posibles interpretaciones ideológicas que propone. En este artículo, se estudia la película en paralelismo con otros usos ideológicos que se hicieron de los mismos mitos clásicos y bíblicos en ese contexto histórico. Especialmente aporta mucha luz sobre el complejo significado de Metropolis la comparación con el proyecto iconográfico del Rockefeller Center de Nueva York, que sigue una estética similar y hace también un uso simbólico de los mitos clásicos de Prometeo y Atlas que aparecen en la película. Sin embargo, mientras que Metrópolis supone una cierta premonición distópica -y preventiva- de la crisis del sueño europeo que presagiaba, por ejemplo, el uso simbólico que de esos mismos mitos se hacía entonces tanto en la URSS como en la Alemania nazi, el Rockefeller Center simboliza -todavía hoy- el proyecto más utópico del sueño capitalista americano. El estudio comparativo entre estos usos diferentes de los mismos mitos griegos muestra que la película de Fritz Lang -ya superados los prejuicios metodológicos heredados de la guerra fría académica- se nos descubre como una obra de arte abierta, considerablemente universal e intemporal.

\begin{abstract}
Almost one hundred years after its premiere, Fritz Lang's Metropolis remains a film of enormous complexity whose possible ideological interpretations continue to provoke controversy. This article studies Metropolis in parallel with other ideological interpretations of the same classic Greek myths explored, such as those of Prometheus and Atlas. In particular, a comparison is made with the iconographic project of the Rockefeller Center in New York, which follows a similar aesthetic and also makes an ideological use of the same myths. However, while Metropolis supposes a certain dystopian and preventive premonition of the crisis of the European dream (as seen in the totalitarian use of the same mythology by both Nazi Germany and the USSR), the Rockefeller Center symbolizes the most utopian project of the American capitalist dream. The comparative study between the distinct applications of these myths in different ideologies results in a renewed reading of the open meanings contained in Fritz Lang's film, which today more than everhaving overcome the methodological prejudices inherited from the Cold War- reveals themselves as universal and timeless.
\end{abstract}

Palabras clave: mitología; cine; Metrópolis; Rockefeller Center; ideología estética; obra de arte abierta.

Keywords: Mythology; Cinema; Metropolis; Rockefeller Center; Aesthetic ideology; Open work of art. 


\section{Introducción}

La relación que se da entre estética e ideología, simbología y política, ha sido estudiada desde finales del siglo XIX en los ámbitos de la filosofía y la teoría de las Artes, pero solo recientemente ha adquirido un protagonismo metodológico en los estudios sobre cine y cultura visual. Y esto ha sido así a pesar de que los medios de difusión masiva han sustituido en muchos aspectos al roll tradicional de "educar deleitando" que ocupaban las bellas artes académicas ${ }^{1}$.

De hecho, es frecuente encontrar en la cultura visual contemporánea constantes referencias a temas y formas artísticas de la tradición plástica occidental, con especial énfasis en los grandes mitos, tanto bíblicos como clásicos. No es extraño que el cine haya heredado esta tradición iconográfica; los mitos son historias de carácter universal que, independientemente de su materialización literaria o plástica, aportan información sobre la sociedad y la vida humana que los reinterpreta dotándoles de nuevos significados. Por eso su constante revitalización, y prolongación más allá del contexto que los creó.

Por supuesto, el cine se inspira también en otras fuentes diferentes a las del arte decimonónico de tradición académica. Por ejemplo, el cine expresionista alemán bebió tanto del simbolismo y de la corriente Jugendstil como de los relatos de Edgar Allan Poe o de E.T.A. Hoffman, y las novelas de Víctor Hugo o de Dostoievski (Eisner, 1988).

\footnotetext{
${ }^{1}$ La fotografía y los medios audiovisuales derivados de su hegemonía -cine, tv, video, etc.han reservado para sí la función figurativa y narrativa que antes tenían las artes tradicionales. Por competencia con estos nuevos lenguajes de grabación de la realidad, las vanguardias artísticas se orientaron hacia la abstracción o la experimentación formal y conceptual, abriendo nuevos caminos para la creatividad. El arte académico, más popular que el de vanguardia, quedó vinculado a los regímenes totalitarios, que lo usaron con fines propagandísticos, o al mundo de la publicidad en el entorno capitalista en el que floreció la estética Art decó de los años 20 y 30, sobre la que vamos a tratar en este artículo, que parte de un análisis del complejo Rockefeller Center y su simbología hecho por Jorge Latorre: Latorre, J. (4 de marzo de 2012). Rockefeller Center: la Atlántida global y sus símbolos [Mensaje en un blog]. Recuperado de https://imagologiajorge.wordpress.com/2012/03/04/rockefeller-center-la-altantida-globaly-sus-simbolos/
} 
La elección de este arte y de esta época en concreto (el cine de la República de Weimar) viene dada porque responde al problema fundamental que se va a abordar en el artículo: aparición de películas con una riqueza simbólica excepcional y en gran medida homogénea (ya que la mayor parte de los documentos siguen la herencia decimonónica señalada), pero que son reflejo de unas ideas muy distintas, dependiendo del director o de la productora que financia la película. Estos significados simbólicos pueden ser incluso opuestos a pesar de pertenecer a la misma corriente y temática, de ahí que el cine expresionista esté considerado como ambiguo en sus mensajes y contenido general.

Sin embargo, el análisis que se hará a continuación va un paso más allá de la complejidad existente en el cine expresionista alemán²: da cuenta de que los imaginarios y símbolos utilizados por cineastas como Fritz Lang se aplican al mismo tiempo en otras artes y otros contextos, por lo que la ambigüedad señalada para el cine expresionista podría aplicarse también a otros ámbitos artísticos del momento estudiado en este artículo.

Por la limitación del espacio, nos ocupamos de analizar solamente algunas de las influencias simbólicas que Metrópolis comparte con las artes plásticas de su tiempo, con especial hincapié en el uso ideológico diverso que se hace de los mitos griegos. Especialmente nos ocuparemos de estudiar la presencia de los mitos de Prometeo y Atlas tanto en la película de Fritz Lang como en los trabajos que escultores nazis y soviéticos realizaron para sus respectivos regímenes totalitarios, según la simbología utópica del momento. Y, con más detalle, analizaremos estos mismos mitos tal como todavía hoy se exhiben en el complejo del Rockefeller Center, con el que tiene muchos puntos en común Metrópolis.

\footnotetext{
${ }^{2}$ La complejidad intrínseca del cine expresionista alemán, así como un análisis iconográfico y narrativo del cine de Fritz Lang, ya la hemos analizado en la tesis doctoral sobre el cineasta (Jiménez González, 2019).
} 


\section{Metodología}

La metodología que vamos a seguir es de carácter histórico artístico e iconológico, con un enfoque especializado en el ámbito de la mitocrítica. La problemática por estudiar en este artículo parte de dos premisas básicas: por un lado, hablamos de mitos en los que se muestran valores abstractos con una fuerte impronta cultural, pero una pretendida aplicación universal; por otro, la apropiación reciente de estos mitos pretende ensalzar ideologías concretas, que difieren entre sí en muchos aspectos políticos y sociales aunque coincidan en su apropiación común del aspecto metafórico original del mito.

Para el tema general de este monográfico interesan sobre todo los paralelismos que se dan entre Metrópolis y el Rockefeller Center, puesto que este último simboliza el nacimiento mismo del "sueño americano", y Metrópolis puede leerse como una propuesta aleccionatoria de los peligros que amenazaban al "sueño europeo", tanto desde el totalitarismo de izquierdas (la revolución y lucha de clases) como desde el totalitarismo de derechas (el fascismo y nacionalsocialismo). Esto último ha sido discutido, pero queda también abierto en la película, como veremos.

Un elemento importante que sirve como punto de partida y factor unitario entre el proyecto de los Rockefeller y el de Fritz Lang, es la estética Art Decó de la gran ciudad futurista, formada por rascacielos, con sus luces de neón y reflejos de cristal agitándose al compás del tráfico abigarrado de los automóviles y otras máquinas modernas. De hecho, el propio Fritz Lang se inspiró en esta ciudad para hacer la película, asegurando que:

Los edificios parecían un velo vertical, brillante, casi ingrávido, una lujosa tela colgada del cielo oscuro para deslumbrar, distraer e hipnotizar. Por la noche, la ciudad no daba la impresión de estar viva; vivía como vivían las ilusiones. Entonces supe que tenía que hacer una película sobre todas estas sensaciones. (McGilligan, 2013, p. 104).

Esta inspiración en Nueva York para la realización de Metrópolis justifica un análisis comparativo profundo entre ambos proyectos, aunque fueran realizados en distintos continentes y con diferentes significados. 
Daría para un artículo completo estudiar estas similitudes estéticas; por eso, metodológicamente vamos a ceñirnos al tema de los mitos de Prometeo y Atlas que adornan puntos emblemáticos del Rockefeller Center, porque eran parte de la cultura del momento, aunque simbolizaran ideas diferentes, como veremos. Estéticamente, beben de varias corrientes artísticas vinculadas con el Art Decó. Destacan la figura de Prometeo (F1), hecha por Paul Manship en material dorado y formas amables, y la de Atlas (F2), realizada por Lee Lawrie y Rene Paul Chambellan, con un estilo más expresionista.

Entre el academicismo y el Art Decó, estas esculturas monumentales comparten rasgos estéticos con el tipo de escultura mitológica que hicieron, en la época en que se construyó el Rockefeller Center, artistas como Arno Breker para el propio Hitler (F3) o Borís Iofán para Stalin3. Aunque volveremos a este tema del arte de los regímenes totalitarios, sirva como ejemplo de esta apropiación de los mitos griegos al servicio del realismo socialista la escultura de Prometeo eregida en Prípiat y trasladada después a Cherbóbil (F4)4.

Por otro lado, si se atiende a la cartelería del estilo Art Decó, popular en la Alemania de Weimar, a propósito de los carteles realizados para la distribución de Metrópolis y su significación, se verá que los imaginarios y la mitología presentes en el cine y el arte que le rodea (decorados, arquitectura, cartelería, etc.) aparecen de forma frecuente en el complejo del Rockefeller Center una década después, aunque la inspiración de ambos partiera de unas mismas fuentes, que son las que vamos a estudiar en este artículo.

3 El pabellón Soviético de la exposición Universal de París de 1937 realizado por Iofan ha sido definido como prometeico en el sentido que estamos estudiando: "Al igual que el pabellón alemán, el monumento de Iofan utilizó la luz para reforzar su propio mito. Mientras Speer erigía un LichtDom congelado que se refería, en un gesto epimeteano, a la profundidad de un folklore mítico, Iofan conjuró la visión de un futuro prometeico que representa la búsqueda de la humanidad por la redención de la autorrealización redentora."(Devos, Ortenberg \& Paperny, 2015, p. 31)

4 Son muchos los prometeos marxistas, quizás el más controvertido sea éste de la figura 4, eregido en un principio en la ciudad de Prípiat, para simbolizar el poder emancipado del ser humano gracias a la energía atómica, y trasladado, tras el desastre núclear, a la central de Chernóbil, mostrando que la rebelión prometeica acaba fracasando por culpa de su desmesurada ambición (Fernández- Vegue, 2017, p. 373). Más cercano al contexto analizado en este artículo, es el Prometeo encadenado que pintó el muralista mexicano David Alfaro Siqueiros, como símbolo de los mártires de la revolución contra el sistema. También José Clemento Orozco pintó en 1930 un mural de Prometeo que sigue esta misma lectura revolucionaria. 

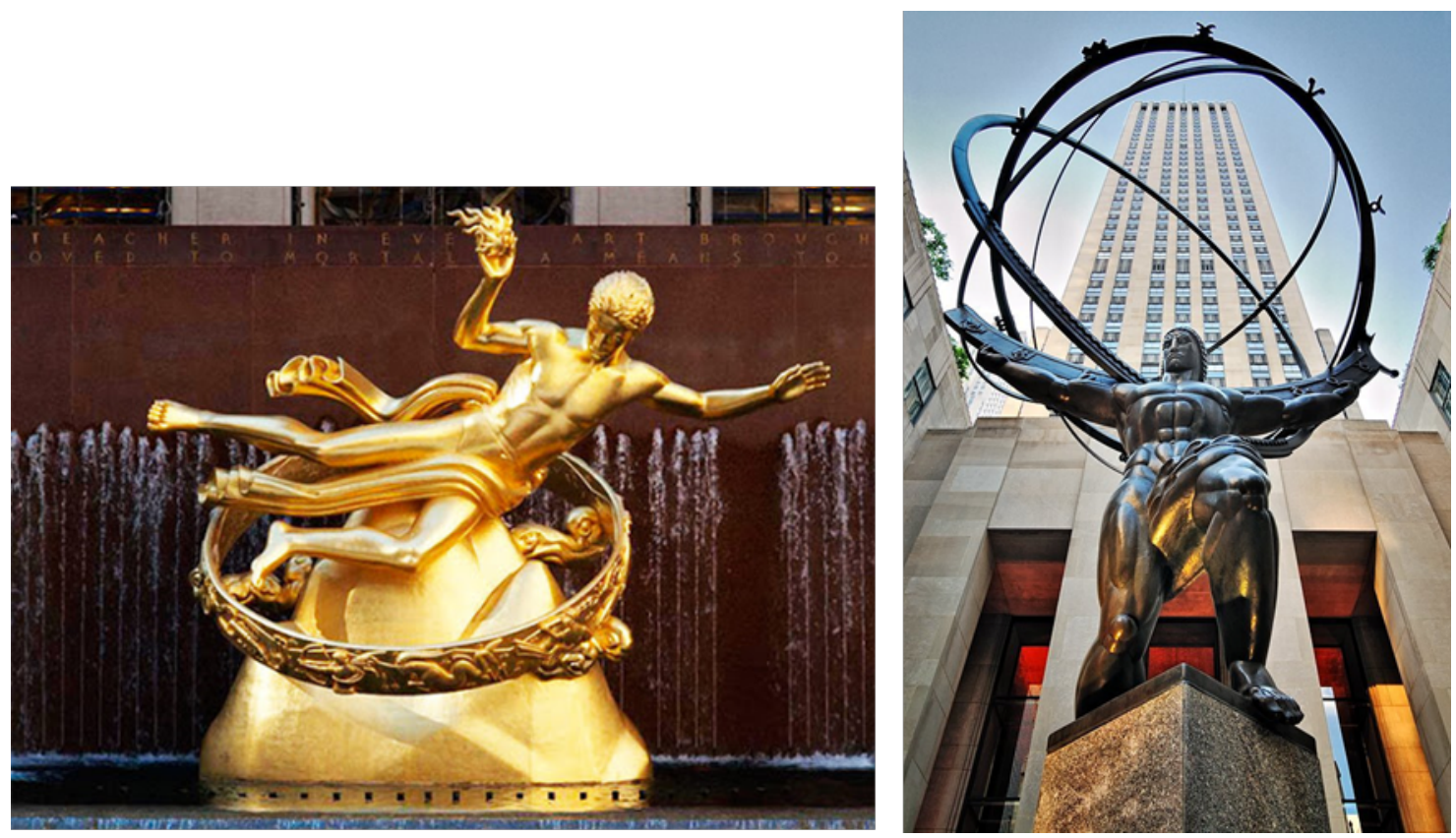

F1. Prometeo. Escultura de Paul Manship, 1934.

F2. Atlas. Escultura de Lee Lawrie y Rene Paul Chambellan ,1937.
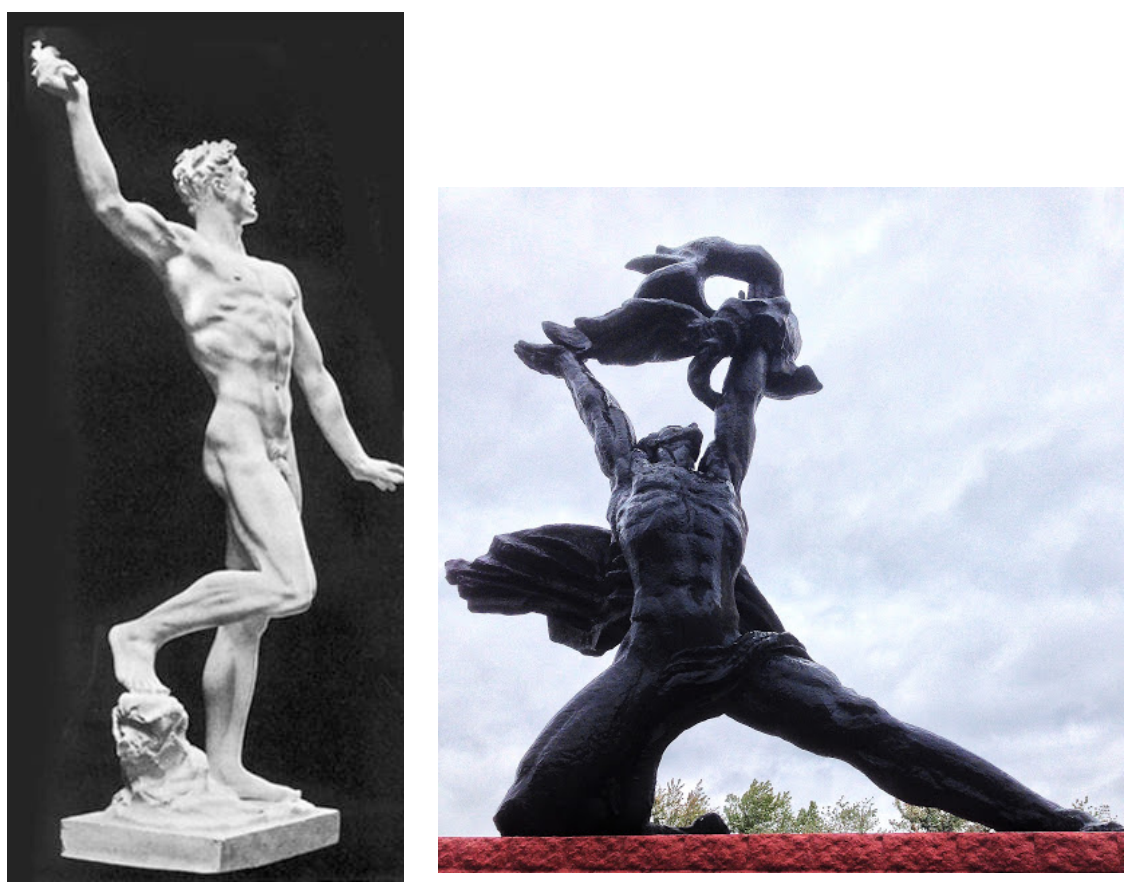

F3. Prometeo. Escultura de Arno Breker, 1937.

F4. Prometeo. Escultura traslada de Prípiat a Chernóbil

La representación del mito y del espíritu prometeico es un buen ejemplo de referencia cultural que, apareciendo en todos los proyectos mencionados con 
una estética similar, responde a cuestiones ideológicas diferentes. En el caso del Rockefeller Center, la escultura de Prometeo va de la mano del pensamiento capitalista y de la mentalidad liberal implícita tanto en la cosmovisión estadounidense como en los valores de la familia Rockefeller. Encarna la utopía del progreso y las ciencias que promueve la libertad del individuo y del capital, que está en la entraña del Sueño Americano.

El Prometeo que Arno Breker hizo para Hitler (1935) encarnaba también una utopía: el ideal ario de liderar a la humanidad hacia un futuro paradisiaco de pureza racial (Featherstone, 2020). Y lo mismo puede decirse de los prometeos del marxismo (tanto los ejemplos del México revolucionario como los de la URSS) que manifestaban el ideal de emancipación del nuevo hombre tecnológico, enfrentado a la tradición y a los viejos dioses, que debían ser arrumbados para construir un mundo sin diferencia de clases, religiones o razas.

En Metrópolis, todo aquello que se puede identificar con el espíritu prometeico es más ambiguo, debido, en primer lugar, al momento histórico en el que se hizo la película, que entremezclaba corrientes artísticas como el expresionismo y la nueva objetividad. A esta estética heterogénea inicial hay que añadir las discrepancias entre los guionistas de la película, tal como cuenta el propio director en una entrevista concedida a William Friedkin:

Cuando la hice me gustó, cuando la terminé, la odié. Por la sencilla razón de que el intermediario entre el capital-cerebro y la mano-el trabajador debe ser el corazón. Yo no lo creía. Después, en los años 50, recibí de forma anónima algunas páginas del Washington Post, en el que el director de una corporación dijo que había visto Metrópolis y que estaba de acuerdo en que es importante tener un corazón para los trabajadores. De cualquier forma, pensé: iAl diablo con eso! Pero después, a finales de los años sesenta, cuando trabajaba de vez en cuando en universidades, en sesiones de preguntas y respuestas, y pregunté a los estudiantes: ¿Qué odian de la sociedad actual? Dijeron que es una sociedad gobernada por computadoras y que la parte que nos hace falta es el corazón. Y pensé que tal vez estaba equivocado y Thea von Harbou tenía razón. (Friedkin, 1975: 12’40”). 
Estas palabras del director ilustran el tercer punto que analizaremos con detalle en el siguiente capítulo: junto a la lectura prometeica emancipadora anterior, Metrópolis recupera además el significado aleccionador del mito, el que invita a la prudencia, como ocurre en El Moderno Prometeo de Mary Shelley que sirve también de inspiración a la película.

\section{Exposición}

\subsection{El espíritu prometeico: la filantropía y el ansia de emancipación y de libertad}

El conflicto que plantea el mito prometeico es, fundamentalmente, la rebelión de un ser limitado (Prometeo) contra otro ilimitado (Zeus). En el origen religioso del mito, el castigo del titán se veía como merecido, o al menos inevitable. Pero si se atiende al motivo por el que el titán se enfrenta al dios (otorgar el fuego a los hombres), el gesto se entenderá como un acto heroico movido por la filantropía y la ayuda a los más débiles. Así lo interpreta ya Esquilo y con esta misma ambigüedad lo describe Carlos García Gual, en la introducción a su estudio Prometeo: mito y tragedia, donde hace un análisis de las distintas versiones de la historia:

$\mathrm{Su}$ motivo para enfrentarse a los grandes dioses es no menos sorprendente: su carácter filántropo le ha llevado a incurrir, con plena conciencia, en la falta trágica que se paga con el más terrible dolor. Por los seres efímeros el Titán Prometeo está dispuesto a desafiar la cólera de Zeus y a sufrir eternamente $[\ldots]$ (p. 12).

La entrega del fuego a los hombres se presenta, por tanto, como un gesto de Prometeo hacia los necesitados, además de como un desafío a los dioses. En esto coincidiría la lectura prometeica que se muestra en Metrópolis con las nazis, soviéticas y la que aparece en el proyecto del Rockefeller Center.

Pero antes de continuar con la exposición del tema, es conveniente señalar que la aplicación del mito a los comportamientos estrictamente humanos implica dar un salto ontológico desde el mundo clásico mitológico al tiempo histórico. Y este salto ontológico o traslado histórico es problemático, como 
ha sido subrayado por autores como Franz Hinkelammert, que advierte sobre la lectura moderna del mito a partir de la cosmovisión antropocéntrica que comienza en el Renacimiento:

Este mito de Prometeo proporciona los elementos para la imaginación prometeica a partir del Renacimiento. Todos los mitos construidos desde el del Prometeo griego tienen un rasgo común, que los distingue a todos del mito griego: en ellos Prometeo es visto como un hombre rebelde que se levanta frente a los dioses, deja de ser un dios y se transforma en hombre. El mito griego sirve más bien como una cantera para la reconstrucción mítica de una rebeldía y emancipación humanas, la cual es realizada por la sociedad moderna a partir del Renacimiento (2006, p. 2).

La advertencia de Hinkelammert implica que a la pretensión filántropa explicada anteriormente se le suma el carácter emancipador con un sentido nuevo. Ya no es tan sólo una rebelión contra el sistema, sino la reivindicación del individuo ante un ser superior, de tal modo que éste pueda igualarse a aquel en derechos y libertades, lo que implica un enfrentamiento. Este espíritu de liberación propio de los humanos que no quieren depender de los dioses es el predominante en las lecturas modernas del mito y el propio de aquellas que resaltan su figura heroica más que trágica. En esta lectura hay que enmarcar por tanto a las distintas ideologías del momento estudiado, tanto las totalitarias (nazismo y estalinismo) como las liberales, entre las que se encuentra el capitalismo defendido por John D. Rockefeller.

Sobre lo que une a ideologías aparentemente opuestas aporta luz la polémica originada con el mural de Diego Rivera que iba a ocupar una posición relevante en el conjunto arquitectónico del Rockefeller Center. Se trata del mural El hombre de la encrucijada, distinado para el vestíbulo del edificio central del Rockefeller (F5). En el centro del mural aparece un científico que controla el universo con la única ayuda de las ciencias y tecnologías. Los dioses han quedado abandonados, ya no son necesarios.

Dicho encargo fue controvertido desde el principio, ya que la familia Rockefeller era un icono del pensamiento individualista y capitalista para la sociedad estadounidense, mientras que Diego Rivera era un pintor 
abiertamente comunista. La participación del artista mexicano en lo que iba a ser un conjunto de edificios que representaran el centro neurálgico del capitalismo extrañó y sigue extrañando a los historiadores. Susana Pliego Quijano sostiene que John D. Rockefeller Jr. encargó el mural a Rivera debido a la admiración que su mujer, Abby Aldrich Rockefeller, profesaba por él, además de por la fama y el reconocimiento que se había labrado en el mundo del arte (2015, p. 7).

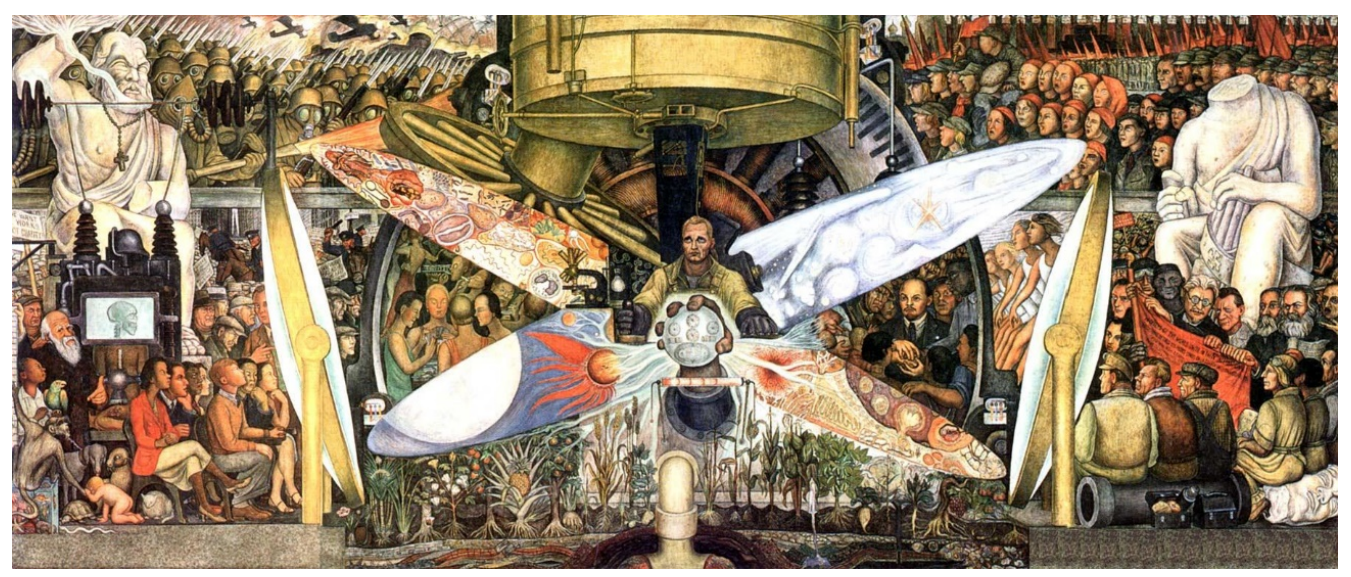

F5. El hombre controlador del universo, de Diego Rivera, 1934. Reconstrucción de El hombre de la encrucijada, para su exhibición en Ciudad de México.

Sin embargo, les unía además a ambos una misma visión prometeica, de carácter utópico. Conviene, por ejemplo, repasar la lectura que el filósofo Karl Marx dio a la figura de Prometeo. El pensador otorgó una importancia especial al carácter libertador del espíritu prometeico en términos estrictamente humanos, en el prefacio de su tesis doctoral. Sostiene que "En el calendario filosófico Prometeo ocupa el lugar más distinguido entre los santos y los mártires" (1971, p. 7), asumiendo que la filosofía, como expresión fundamental del pensamiento humano, debe enfrentarse a las "deidades celestiales y terrestres”, gozando de autonomía sin sometimiento alguno. Además, tal y como menciona Hinkelammert, la versión prometeica de Marx es el punto de partida para concebir la historia de Prometeo en una dimensión humana: "El dios-titán Prometeo se hizo hombre, para que los hombres se hagan Prometeo" (2006, p. 8), esta es la clave de la interpretación moderna y contemporánea del mito. 
En este sentido, el problema que llevó a la destrucción final del mural (que fue después pintado en Ciudad de México) no se dio únicamente porque Rivera tuviera una ideología izquierdista, sino porque en el propio fresco imprimió una crítica feroz al capitalismo, ensalzando los valores comunistas en el mismo corazón del capitalismo, cosa que supuso un desafío continuo para la familia. El punto de inflexión fue la representación de Lenin, como símbolo de unión entre los trabajadores, como líder que guía a "las masas explotadas a un orden social basado en la supresión de clases" (Rivera, 1934, p. 27). Dicho retrato, junto al de otras grandes personalidades socialistas, como Marx, Engels o León Trotski, fue el detonante para que Rockefeller decidiera destruir la obra y encargársela al pintor catalán Josep María Sert.

Por supuesto, si se atiende al ámbito político, las interpretaciones del mito prometeico pueden variar con matices importantes según se trate de un materialismo teórico o más práctico y vitalista: lo que en Marx era libertad de pensamiento que precede a la revolución, en el Rockefeller Center pasa a ser libertad individual y económica para hacer del mundo un lugar más próspero para todos los seres humanos. Y en esta lectura entrarían también las visiones de Prometeo que hicieron los nacionalsocialistas, vinculadas tanto a las tradiciones mitológicas germánicas como a las griegas.

Por ejemplo, una interpretación común en la Alemania del siglo XIX y principios del XX fue la similitud entre la figura de Sigfrido, protagonista de El cantar de los nibelungos y de las películas que realizó Fritz Lang sobre el relato medieval, y Prometeo, en el sentido de ser un icono de autonomía y de libertad, al enfrentarse a las circunstancias contra todo pronóstico de victoria. Así lo recuerda Rüdiger Safranski, a propósito de Richard Wagner, en su estudio sobre el romanticismo alemán: "La figura de Sigfrido es para él (para Wagner) una encarnación de la libertad en consonancia con esa pauta, [...] Sigfrido es para él un nuevo Prometeo, y también un nuevo Cristo." (2009, p. 238). Los nazis también entendieron la figura de Sigfrido como propia, al interpretarla como símbolo de libertad, fuerza y belleza. Prueba de ello fue el reestreno de la primera parte de la película de Lang: La muerte de 
Sigfrido (1924), en mayo de 1933, poco tiempo después de que llegaran al poder.

Se puede ver que todas las interpretaciones prometeicas en clave utópica parten de la invitación a toma las riendas de la historia y a servirse de un poder tecnológico que hasta ese momento solo había pertenecido a los dioses (tal y como recita la frase de Esquilo plasmada detrás de la escultura de Prometeo en el Rockefeller Center). Esto es, el Prometeo del capitalismo manifiesta también un cararter utópico liberador del espíritu, gracias al dominio de la tecnología que otorgaba el progreso material, lo que también defendía la ideología comunista y la de los regímenes totalitarios de extrema derecha entonces en auge.

Es preciso dar cuenta de este elemento compartido por todas las ideologías del momento, del carácter prometeico de transformación social que estos polos ideológicamente opuestos tenían como fundamento, para poder entender la complejidad que este símbolo presenta en Metrópolis. Pues la película de Fritz Lang ha sido considerada tanto defensora de la lucha de clases como del capitalismo y del fascismo5. Veremos a continuación que esta confusión que Metrópolis produce entre los críticos no es necesariamente un inconveniente o cortapisa. Al contrario, puede ser un signo de su riqueza, puesto que las grandes obras de arte se caracterizan por su apertura (Eco, 1965); o lo que es similar, por trascender con propuestas de complejidad las ideologías dominantes en el contexto que las vio nacer.

\subsection{La complejidad del mito prometeico en Metrópolis}

Una vez que se ha explicado la ambigüedad ideológica (con un trasfondo de valores similares) del mito prometeico y su aparición en el proyecto artístico

\footnotetext{
5 Algunos sectores de la crítica la calificaron como una película con tendencias comunistas, que incitaba a la rebelión y a la revolución. Thomas Elseasser, en su estudio sobre el filme (Elsaesser, 2000), recuerda que en algunos países como Italia y Turquía, por ejemplo, fue retirada de los cines por sus tendencias "bolcheviques". Por su parte, Patrick McGilligan menciona estos recortes en su obra ya citada, incluyendo los que se aplicaron a la versión americana (2013, p. 131). Por otro lado, la vinculación de la película con el nazismo está encabezada por Sigfried Kracauer, al identificar los discursos del protagonista con los de altos dirigentes nacionalsocialistas (1985, p. 155). Dicha lectura está más extendida y fue apoyada influyentes teóricos del cine, como Francis Courtade, quien sostuvo que Metrópolis era "una obra fascista pre-nazi” (Francis Couertade citado en Gil Olivo, 2005, p. 60).
} 
y arquitectónico de la familia Rockefeller, y también en el mundo nazi y soviético, se pasará a analizar el modo en el que dicho mito aparece en la película de Fritz Lang, cuestión más compleja, ya que entremezcla algunas de las lecturas mencionadas anteriormente con la visión del mito defendida por Mary Shelley en su obra Frankenstein, o el moderno Prometeo (1818).

Metrópolis fue una película innovadora para la época, en la que se unieron muchas de las tradiciones cinematográficas y culturales existentes en la Alemania contemporánea, manifestándose de diversas maneras en el arte de la década de los años veinte. Asimismo, la trama y los personajes reflejan ideas políticas y religiosas que la convierten en una de las películas más complejas de su tiempo, llegando a conformar, de acuerdo con las palabras de Vicente Sánchez-Biosca, un síntoma de la Alemania de Weimar (2004, pp. 116-117). El autor utiliza la palabra "síntoma" refiriéndose al híbrido entre las distintas tradiciones y pensamientos mencionados, al ser un trabajo hecho en pleno periodo de estabilización de la República de Weimar, en el que hay un cambio de pensamiento y una evolución en la sociedad y en el arte (Klein, 1970). Ante esta situación, no se puede concebir a Metrópolis como un filme políticamente definido o como un documento que posee una lectura homogénea en cuanto a ideología se refiere, sino, más bien, como un filme que presenta un conjunto de ideas entremezcladas que son, precisamente, las que han provocado las ya históricas polémicas en cuanto a su lectura política, identificándola, en varias ocasiones, como nacionalsocialista o comunista.

Esta ambigüedad aparece también en la construcción de los personajes y en la representación de varios mitos e historias bíblicas que, reflejando temas eternos, se interpretan de una forma o de otra dependiendo del contexto. Por ello, y volviendo al tema central del artículo, aunque la mitología clásica implícita en la película represente valores humanos, tales como la ambición o la soberbia, las interpretaciones que se derivan de ella pueden ser muy variadas, y se dan tanto en la trama general como en determinados personajes. Por ejemplo, para analizar la vertiente filantrópica del mito prometeico, es preciso analizar el personaje de Freder, el protagonista, cuya construcción es compleja, ya que atraviesa varias fases y puede relacionarse 
con algunos personajes bíblicos y de la cultura clásica. Para ello, se explicará quién es y se describirá brevemente el argumento.

El preámbulo de la historia es el de una ciudad dividida en dos partes muy diferenciadas: la superior y la inferior. En la primera viven las personas acomodadas, los aristócratas, que gozan de una vida idílica; en la parte subterránea, los trabajadores, los obreros, que trabajan exhaustivamente para sostener la agradable vida de aquellos. Dicha situación estamental cambia cuando María, habitante de la superficie, desea ayudar a unos niños poco favorecidos y, al enseñarles los "jardines eternos" se encuentra con Freder, otro habitante de la zona privilegiada e hijo de Joh Fredersen, el denominado "Amo de Metrópolis", porque controla toda la ciudad. Intrigado y al ver su situación, Freder decide bajar y observar el modo de vida de los habitantes del subsuelo. Allí ve las duras condiciones de trabajo a las que están sometidos y la alienación a la que están condenados; en definitiva, contempla el sufrimiento y la pésima calidad de vida que llevan. Es entonces cuando Freder se dirige a su padre para pedirle explicaciones. El protagonista se da cuenta del trato denigrante que Joh da a los trabajadores y decide bajar a las profundidades para ayudarlos.

El carácter filántropo de Freder, al ser un habitante de la superficie que desea ayudar a los desfavorecidos, facilita la identificación entre su comportamiento y el de Prometeo al desear "aunque solo fuera por una vez, mirar los rostros de esos hombres, estos hombres cuyos hijos son mis hermanos, cuyas hijas son mis hermanas... [...] (Von Harbou, 1977, p. 106). Además, si se tiene en cuenta que esta pretensión implica un enfrentamiento directo con su padre, a quien los habitantes de la ciudad consideran un dios (von Harbou, 1977, 106), la identificación será todavía mayor (F6).

Estas premisas permiten asociar el comportamiento de Freder con el de Prometeo y el de Joh Fredersen con el de Zeus. La lucha contra el padre sucede durante el preludio, ${ }^{6} \mathrm{y}$, en un acto de altruismo, ante su negativa, el

${ }^{6} \mathrm{Si}$ bien las intenciones de Freder al comienzo del filme son prometeicas (la lucha contra el padre poderoso) durante el desarrollo del mismo se convierte en un personaje mesiánico, alejado del heroísmo trágico de Prometeo. Esto sucede porque es un personaje que evoluciona a medida que avanza el metraje, atravesando varias fases. De la construcción 
protagonista decide ayudar a los desfavorecidos, a los obreros que soportan unas condiciones inhumanas. Desde el principio se detecta una lucha de esta índole, ya que, aun perteneciendo al privilegiado mundo de la superficie, se enfrenta a la máxima autoridad para ayudarlos. Se trata de la entrega del fuego, trasportada al siglo $\mathrm{XX}$, entendiendo el fuego como derechos laborales. De este modo, Freder se enfrentará a Joh Fredersen por motivos similares a los que Prometeo se enfrenta a Zeus; por atender a seres necesitados. Sin embargo, ya no será una ayuda de dioses a hombres, sino entre hombres, de privilegiados a desfavorecidos, de aristócratas a trabajadores; en definitiva, una ayuda entre clases, adaptada al cambio ontológico analizado anteriormente.

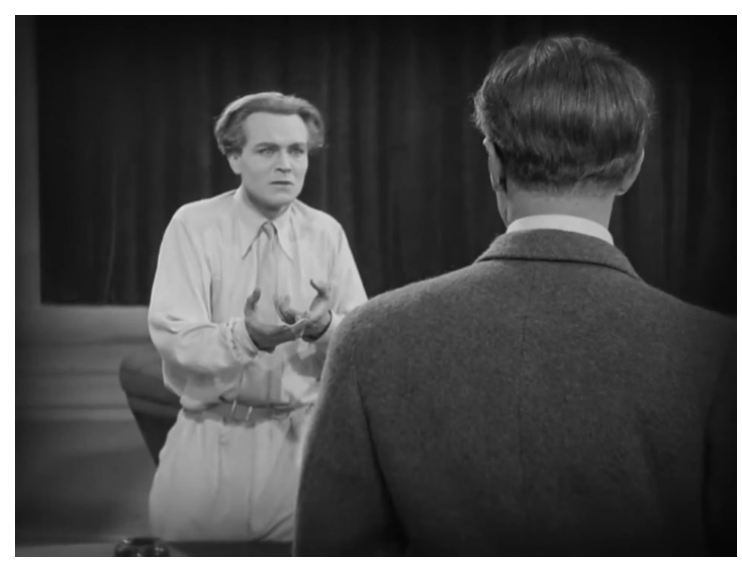

F6. El enfrentamiento contra el padre. Fotograma de Metrópolis, de Fritz Lang, 1927

A la lectura moderna del mito, que refleja el valor de la filantropía, se le suma su versión clásica, recuperada por Mary Shelley, que expresa el de la rebelión contra el orden natural. Y, aunque este valor de la rebelión ya estaba implícito en el acto del enfrentamiento contra el padre de Freder, existe otro modo de representarlo, esta vez mediante el personaje de Rotwang, el científico que crea un ser-máquina incansable con el que pretende sustituir la incapacidad de los obreros. La construcción de este personaje otorga a la historia una fuerte carga política y filosófica, ya que a través del ser-máquina

compleja de Freder han dado cuenta varios teóricos, entre los que destaca Paolo Bertetto, investigador de cine que en su obra sobre la película señaló que Freder es un personaje en continua formación, al estilo de los protagonistas de las novelas de formación alemanas, como Los años de aprendizaje de Wilhelm Meister (1795-1796), de Goethe. Asimismo, también señala la similitud entre Freder y Sigfrido, resaltando el carácter de héroe trágico prometeico (Bertetto, 1990, p. 82). 
se plantean problemas relacionados con los derechos de los obreros, al significar una amenaza para ellos, y se abordan cuestiones relacionadas con teorías como el transhumanismo, corriente filosófica nacida en el siglo XIX cuya premisa principal es la necesidad de superar al ser humano, ya que se le concibe de una forma pesimista (Urraco Solanilla y Martínez Mesa, 2019). En el escrito de von Harbou ya aparecen párrafos de corte transhumanista, en los que se percibe una visión pesimista de los humanos en favor de las máquinas, que suplen sus carencias (pp. 29-30).

La actitud prometeica que muestra el científico se refleja en la pretensión de equipararse a los dioses, creando un robot antropomorfo animado, en definitiva, una nueva forma de vida, del mismo modo en el que lo hace Víctor Frankenstein en la novela anteriormente menciona de Mary Shelley. El desafío consiste en querer alcanzar la grandeza de los dioses a través del fenómeno de la creación de vida, otorgando al ser humano un poder que no le corresponde.

En el cine y en la literatura se denomina a este fenómeno como el imaginario estético de la segunda creación, ya que traslada el ansia de libertad y de poder prometeica al ser humano que, disponiendo de la técnica necesaria, genera un ser vivo a su imagen y semejanza. De este modo, el primer ser creado (el humano) genera otro ser (monstruo o máquina) que supondría la segunda creación. Y, aunque es cierto que en el Rockefeller Center el mito es ejemplar y en las obras que representan la segunda creación es preventivo, es decir, que se advierte de los peligros que conlleva querer asemejarse a dios, resulta necesario señalar su existencia para subrayar la amplitud de la simbología prometeica, y el carácter soberbio y rebelde de la lectura del mito que también aparece en la película. En Metrópolis, Freder presenta una actitud prometeica moderna y Rotwang una estrictamente clásica; no obstante, ambas responden a las mismas necesidades humanas de querer saber lo que le está vedado al hombre conocer, algo que enlaza también con los mitos bíblicos del libro del Génesis, que aparecen también en la película con un significado igualmente abierto que la interpretación de Prometeo. 
En conclusión, Metrópolis solo en parte comparte el simbolismo prometeico de la ciudad moderna que encarna pocos años después el Rockefeller Center. El fin de la familia Rockefeller era reflejar el mito redentor de Prometeo en un proyecto arquitectónico que interactúa directamente con los ciudadanos de Nueva York. Es decir, que forma parte de su vida cotidiana, y responde a una pretensión efectista de la arquitectura, propia de "los individuos poderosos que quieren dejar su impronta” (Sudjic, 2010, p. 290). John D. Rockefeller Jr. quería dejar huella, y lo hizo sirviéndose de la misma mitología que utilizaron en sus construcciones y proyectos políticos megalómanos como Hitler o Stalin. Eran proyectos totalitarios diferentes del pensamiento liberal capitalista, pero que muestran en su significado prometeico una relación similar con el poder7.

Por el contrario, la utilización polisémica del mito de Prometeo que hace Metrópolis, además de manifestar la apertura de las grandes obras de arte, permite una lectura aleccionadora y preventiva de los peligros que amenazaban al sueño europeo, que en esa época se identifica todavía con el sueño amable de la cultura occidental como civilizadora del mundo desde la prudencia y la humildad, desde el corazón como intermediario de la cabeza y las manos. La propuesta no es necesariamente cristiana, pese a la presencia constante de estos símbolos en la película, pero menos todavía se adecúa con la lectura nacionalsocialista del elegido como lider de masas. No hay en Metropolis una propuesta ideológica clara, salvo la prevención contra los humanismos arrogantes de las utopías totalitarias del momento, como supo describir años después Henry de Lubac.

Según Henry De Lubac (1993), a finales del siglo XIX surgió un humanismo ateo que pretendía sustituir a la civilización cristiana. Lo que la sociedad judeocristiana había percibido anteriormente como liberación, ahora los teóricos del humanismo ateo lo consideraban una esclavitud. La grandeza humana exigía el rechazo del Dios de la Biblia. La novedad del periodo que estamos analizando era que no se trataba ya de individuos aislados

7 La relación de estas tres ideologías con el neoclasicismo la hemos trabajado en Jiménez González, Marcos, Romanticismo, técnica y poder en la arquitectura de Albert Speer, Madrid, Ápeiron ediciones, 2018. 
desasosegando o impresionando a sus congéneres sino toda una ideología bien desarrollada y con un programa para reformar el mundo. En el corazón de la oscuridad que obcecaba a las grandes tiranías de mediados del siglo XX, como el comunismo, el fascismo, el nazismo, de Lubac descubría los mortíferos efectos de un contubernio entre la tecnología moderna y las ideas del humanismo ateo ${ }^{8}$. Este humanismo ateo culmina en las dos grandes ideologías totalitarias que dividen a Europa antes de la Segunda Guerra Mundial. Como predijo Metrópolis, era el fin del sueño europeo encarnado en la ciudad del futuro; y también el comienzo del sueño americano simbolizado por el Rockefeller Center.

\subsection{El mito de Atlas: ¿quién sostiene el mundo y quién se rebela?}

La figura de Atlas, titán de la mitología griega y hermano de Prometeo, también posee significado en la sociedad moderna. Si Zeus castigó a Prometeo a que un águila devorase su hígado eternamente, a Atlas le hará sostener los pilares de la Tierra sobre sus hombros, después de ser derrotado en la guerra contra el Olimpo. Así, sus múltiples representaciones reflejan una figura humana sosteniendo el universo, tal y como ocurre con la escultura más famosa del Rockefeller Center (F2).

Tanto la escultura de Atlas como la de Prometeo beben de un estilo neoclásico exagerado, similar al que fue habitual en la Alemania nazi o en el arte soviético (bajo el nombre de realismo socialista), y que hacían gala de un culto al cuerpo idealizado. Un ideal estético que era habitual también en los denominados Kulturfilme o películas culturales alemanas de los años 20. Esto es, se trata de una estética que servía para ideologías muy diferentes, y también lo hacían los mitos con ella representados. En el caso particular de Atlas, la relación que se viene estableciendo en el escrito reaparece de la mano del cartel hecho por el diseñador húngaro Jósef Bottlik que, en la línea

\footnotetext{
8 El humanismo ateo hizo suyos los principios del positivismo de Conte (la ciencia como única guía fiable de la humanidad), Feuerbach y su subjetivismo (Dios es la proyección mítica de las aspiraciones humanas), Marx con el materialismo (el mundo espiritual es pura ilusión) y Nieztsche y su obstinación radical (la voluntad de poder es el mayor exponente de la grandeza humana). El caldo de cultivo para la afloración de los totalitarismos estaba perfectamente sembrado (cf. también Overy, 2006).
} 
de otros cartelistas, como Heinz Schulz-Neudamm, realizó un dibujo que seguía el estilo Art Decó imperante en la cartelería de la época (F7)9.

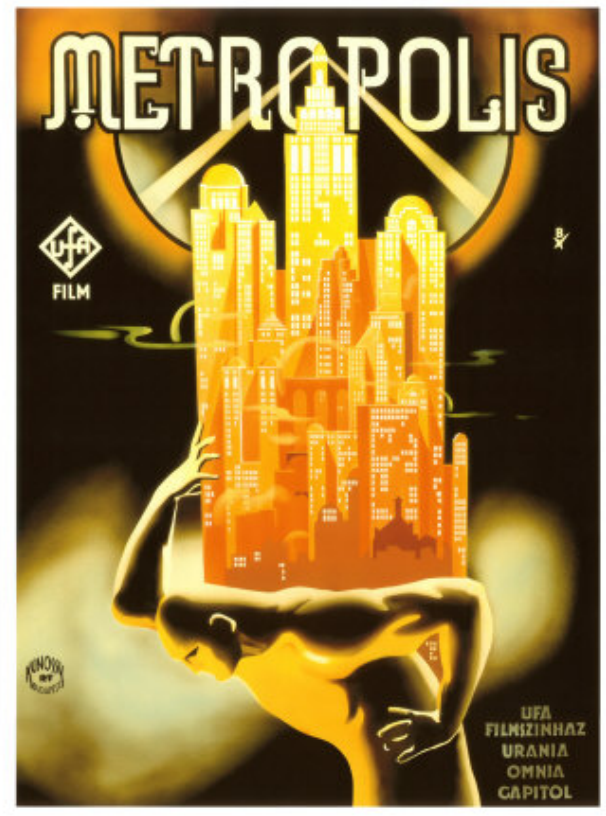

F7. Representación de Atlas en la cartelería promocional de Metrópolis. Cartel para su estreno en Hungría, de Jósef Bottlik 1927.

De acuerdo con la Budapest Poster Gallery, en el diseño de Bottlik aparece la figura de un obrero sosteniendo la ciudad sobre sus hombros ${ }^{10}$, otorgando a la figura del titán, nuevamente, significaciones políticas. Así, vuelve a aparecer la dicotomía entre un ser inferior y uno superior, la lucha del titán contra el dios, ya traducida en la lucha del hombre contra la divinidad; que, aplicada en su totalidad a Metrópolis, aparece como la lucha del hombre contra una ciudad que le absorbe. En la película son los obreros quienes se ven obligados con su trabajo esforzado a mantener la ciudad, al igual que Atlas sostiene el universo. Asimismo, Freder, mediador-corazón de las dos partes de la ciudad, ayudará a los obreros a sostenerla y a no rebelarse contra su padre (el Amo de Metrópolis) y los habitantes de la superficie, ya que

\footnotetext{
9 Los carteles más conocidos de la película están diseñados por Heinz Schulz-Neudamm, ilustrador alemán que hizo multitud de encargos para las películas de la época de Weimar y preparó los carteles para el estreno de la película en Berlín, el 10 de febrero de 1927. El diseño de Jósef Bottlik no es tan conocido porque fue realizado únicamente para su lanzamiento en Hungría ese mismo año.

10 "En su póster de Metrópolis, una figura gigantesca de un obrero lleva los rascacielos de una ciudad imaginaria sobre su espalda. El póster resume la película en una escena monumental" (Budapest Poster Gallery. (2020). Bottlik, József 1897 - 1984. Recuperado de https://budapestposter.com/artists/jozsef-bottlik).
} 
pensaba que la revuelta causaría inevitablemente la destrucción total de la ciudad.

Si se establece una comparación entre el Atlas de Rockefeller Center y el uso que de este mismo mito hace Metrópolis, se podrá entender en gran parte la contraposición política imperante en la segunda mitad del siglo XX entre capitalismo y comunismo, y el eclipse del sueño europeo que anunciaba la película de Fritz Lang. Esto es, con el salto ontológico del mito de Atlas ocurre prácticamente lo mismo que hemos visto ya en relación con la historia de Prometeo.

El cartel realizado por la UFA para la película refleja la figura de Atlas al igual que la escultura del Rockefeller Center; no obstante, lo hace de nuevo con una pretensión política distinta. En el filme de Lang, los trabajadores, cansados de ser esclavos y "siervos de los seres de la superficie" (von Harbou, 1977, p. 7), adquieren, a medida que avanza la historia, pretensiones de rebelión. Freder y María serán quienes controlen dichas pretensiones, incitándolos a que aguarden la llegada del mediador-corazón, que unirá a las dos partes antitéticas de la narración. La rebelión ansiada por los obreros surge de la situación esclavista que atraviesan, de tener que vigilar eternamente las máquinas para que la ciudad no se derrumbe. Por tanto, se puede afirmar que su levantamiento está motivado por la gran responsabilidad que supone tener que cargar eternamente sobre sus hombros con el funcionamiento de la ciudad; una carga que se presenta como una condena de la que no pueden escapar.

De acuerdo con esta lectura, que explica en gran medida el cartel de la película, el fundamento ideológico fundamental planteado por Metrópolis sería la lucha de clases, en la línea del pensamiento socialista o comunista. Sin embargo, ya hemos visto que la resolución del conflicto va de la mano de una única persona, Freder, el mediador-corazón, que es precisamente el que le otorga la interpretación mesiánica -o la interpretación fascista, según algunos investigadores- al depender la sociedad de un único individuo necesario (Dadoum, 1991). De nuevo, y aunque el significado del cartel de Atlas hecho por Jósef Bottlik sí sea preciso, es prácticamente imposible hacer 
una lectura ideológica definida del filme en general. Pero la presencia de este mito paralelo al de Prometeo en Metrópolis quizás ayude a explicar lo que, como denuncia del problema que atentaba contra el sueño europeo, unía a los socialismos internacionales y nacionalsocialismos del momento.

La figura de Atlas conforma una posición importante también en el complejo del Rockefeller Center, pero presenta otra significación. Si la revuelta de los obreros en Metrópolis es de corte socialista, al pretender equipararse a la revolución rusa de 1917 y a las revueltas espartaquistas sucedidas en 1919 al principio de la República de Weimari11, la interpretación de Atlas en el proyecto de Rockefeller estará relacionada con el pensamiento liberal y capitalista. Un pensamiento que sería expuesto, años después, en obras como La rebelión de Atlas (1957), de Ayn Rand, donde se describe una rebelión en unos términos muy distintos y opuestos a los de la película de Lang.

Parece que la autora se inspiró en el Rockefeller Center para dotar al mito de Atlas de la misma significación política (Caño Diaz, 2018, p. 60). En el escrito se produce una revuelta a la inversa de la que se ha explicado a propósito de Metrópolis, ya que son precisamente los empresarios los que se rebelan y hacen que el mundo deje de funcionar.

No se trata ya de la clásica revolución obrera de corte marxista, sino de una revolución liberal e individualista, basada en los principios de la filosofía objetivista de Rand, que enfrenta a los sujetos contra un Estado que pretende intervenir en las decisiones de los ciudadanos. Estamos, pues, ante la revolución de los empresarios, que también tendrán un líder que guíe su causa. En este caso es John Galt, el empresario que promueve la huelga y está cerrando paulatinamente los proyectos industriales del país.

Curiosamente, el Freder de Metrópolis sería entonces lo más parecido al John Galt de La rebelión de Atlas, incluso presentando los mismos rasgos

${ }^{11}$ Nótese la relación de las revueltas de la película con la Revolución francesa. En las escenas donde se organizan rebeliones hay un leitmotiv cuyas notas son muy similares al himno francés, por lo que cada vez que aparezca una escena revolucionaría el espectador escuchará esa melodía, que se asociará con el acontecimiento de 1789. La música original está compuesta por Gottfried Huppertz, pero a lo largo del siglo pasado ha sido modificada y sustituida por otras composiciones, como las de Giorgio Moroder o Abel Korzeniowski, entre otros. 
heroicos y mesiánicos. Además, si la figura de Atlas en la película se asociaba con los obreros que sostenían la ciudad mediante su exhaustivo trabajo (idea central del cartel analizado), la simbología que ofrece en la novela de Rand es la de los empresarios que cargan con el funcionamiento del mundo, en una sociedad dominada por el pensamiento liberal e individualista (Caño Diaz, 2018, p. 66). Así, los empresarios ansían la rebelión del mismo modo en el que lo hacen los obreros de Metrópolis, y ello da título al escrito (Caño Diaz, 2018 p. 65). Rand lo expresa de la siguiente manera:

-Sr. Rearden -dijo Francisco con voz solemne y calma-, si viera a Atlas, el gigante que sostiene al mundo sobre sus hombros, de pie, corriéndole la sangre por el pecho, con las rodillas dobladas y los brazos temblorosos, intentando hacer acopio de sus últimas fuerzas, mientras el globo pesa más y más sobre él, ¿qué le diría que hiciera?

-Pues... no lo sé. ¿Qué... podría hacer? ¿Qué le diría usted?

-Que se rebelara. $(2005,416)^{12}$.

La relación entre la escultura de Atlas del Rockefeller Center y la interpretación que se hace del titán en la novela de Rand no es casual. Ambas fomentan la idea de que el individuo debe tomar las riendas y encargarse él mismo de las decisiones que dominarán su vida, frente a una sociedad o un sistema de valores que le obliga a vivir de acuerdo con unas reglas que él no ha decidido. Se trata en definitiva de la oposición entre liberalismo y comunitarismo, que se traduce en última instancia en el enfrentamiento entre capitalismo y socialismo característico de la Guerra Fría.

Por tanto, la figura de Atlas, así como la de Prometeo, puede aplicarse a multitud de lecturas políticas, adaptándose también a la tercera vía que se ha tratado en estas páginas: la de identificar al titán con la figura del ser necesario o mediador, de relacionarlo con el individuo del que dependen

${ }_{12}$ Es cierto que la palabra "rebelión" aparece en las traducciones al español del escrito, ya que en inglés se utiliza el término Shrugged, que literalmente significa encogerse de hombros. No obstante, el significado es el mismo, ya que si Atlas se encoge de hombros el mundo que sostiene se cae, y eso es precisamente lo que pretenden los empresarios con su revolución. 
tanto los obreros como los empresarios, o la sociedad en general; es decir, asociarlo con Freder y John Galt, respectivamente.

Dicha relación, si bien podría estar implícita en el cartel de Metrópolis diseñado por Bottlik, no se da explícitamente en la película; y, sin embargo, es necesario traerla a colación a propósito de un cartel publicitario hecho para la película Batman (Tim Burton,1989) (F8). El cartel tiene exactamente la misma estructura visual que el de Jósef Bottlik, pero abre una nueva interpretación del mismo mito, al ser Batman, el protagonista y héroe del filme, quien sostiene la ciudad de Gotham sobre sus hombros y no un obrero o un empresario anónimos, como ocurría en las dos lecturas anteriores. En este caso, la figura de Batman como mediador sí que puede asimilarse con lo que Freder representa en Metrópolis, por lo que cabría también en la película esta lectura intermedia del mito de Atlas asociado con la supervivencia de la gran ciudad y lo que simboliza de sueño europeo (como Batman lo es del sueño americano).

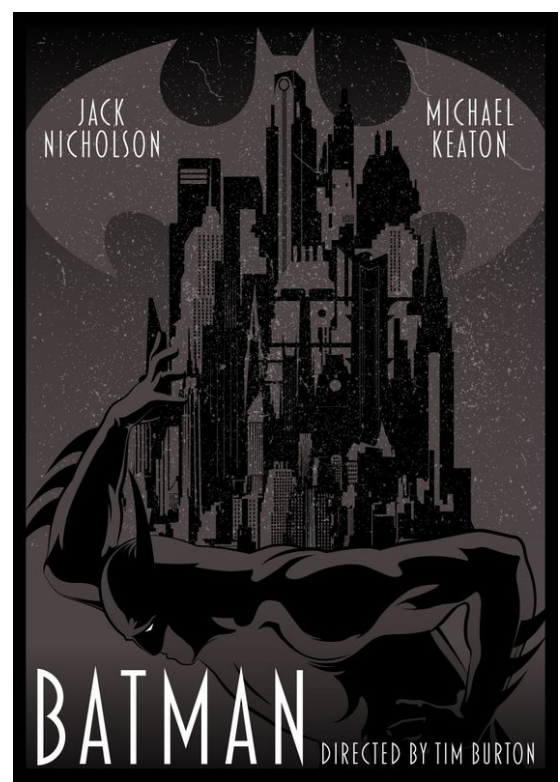

F 8. Representación de Atlas en la cartelería promocional de Batman. Cartel de Ciarán O'Donovan, 1989.

Atlas y Prometeo son titanes hermanos, y pueden significar la misma rebeldía. Hemos visto que en el comunismo, la figura de Prometeo simbolizaba la lucha del proletariado contra la burguesía, buscando la emancipación de los trabajadores. Lo hemos visto con ejemplos de Diego Rivera y otros muralistas mexicanos, algunas interpretaciones soviéticas e 
incluso el cartel de Metrópolis leído en clave de lucha de clases. En el caso del nacionalsocialismo, simbolizaba la exaltación de una figura heroica que guíe el destino de una sociedad hacia la pureza ideal. Y en el capitalismo, lo hace a través de la exaltación de la libertad individual y creativa frente al colectivismo del sometimiento (Rockefeller Center: teacher in every art).

Estas facetas emancipadoras del mito estarían también presentes en el Atlas del Rockefeller Center, enfrentado desde ese conjunto de Lichtdom, o catedrales de luz (por usar el término creado por Speer para este tipo de estructuras verticales infinitas), que son los rascacielos del complejo urbanístico, a la portada de la catedral católica de San Patricio, justo al otro lado de la Quinta avenida. Como un nuevo mesías poderoso que carga con el cosmos en vez de con la cruz, Atlas parece enfrentarse al símbolo de una Iglesia, la católica, anclada en el pasado, y muy poco americana según la visión del propio John D. Rockefeller, conocido masón (como lo era también Diego Rivera, lo que puede explicar en parte el encargo inicial del mural frustrado a este pintor comunista).

No es extraño que ese Atlas enfrentado a San Patricio sirviera de modelo para el libro de Ayn Rand, en el que el personaje mítico es identificado con los emprendedores del capitalismo, que miran más al futuro que al pasado, y desprecian por tanto las ideas colectivistas de las instituciones religiosas. Esto es, las múltiples interpretaciones se fundamentan en los mismos imaginarios y en una similar tradición cultural moderna y revolucionaria; y la confusión solo depende de la parte del mito que seleccionan las tendencias políticas que se apropian de su significado con fines utópicos, según la situación social o el contexto (nacionalista, socialista o capitalista).

\section{Conclusiones: una tradición mitológica similar aplicable a múltiples ideologías}

La universalidad propia de estos imaginarios, y el porqué de su aplicación en multitud de artes, se debe en primer lugar a que son la base de la cultura europea, en la que está fundamentada también la estadounidense; y, en 
segundo lugar, a que tratan temas atemporales y aplicables a cualquier tendencia ideológica. La lucha del débil contra el fuerte puede aplicarse a cualquier ideología dependiendo del contexto histórico y de la manera en la que se exprese. Prometeo es un mártir del calendario filosófico, pero también lo es del capitalista, y en su día lo fue del nacionalsocialista y del comunista. Esto demuestra que, más allá de ideologías concretas, su figura, así como la de otros seres mitológicos, refleja una actitud humana que trasciende todas las opiniones políticas; refleja, en cualquiera de los casos descritos, el carácter utópico implícito en los seres humanos.

También en Metrópolis están presentes los temas eternos de la contraposición entre débiles y fuertes, así como la lucha utópica que busca la liberación, aunque se haga desde una lectura ideológica diferente a las antes señaladas. Freder, antes de convertirse en el mediador-corazón, se rebela contra su padre para ayudar a los obreros en un acto filantrópico propio del mito prometeico moderno; por su parte, Rotwang, pretende equipararse a Dios al crear un ser-máquina que sustituya y supere a los humanos en fuerza de trabajo y capacidades, recordando así el imaginario estético decimonónico de la segunda creación, la de Mary Shelley, que retoma el sentido original del mito clásico (a pesar de que se tituló El Moderno Prometeo). La rebelión de esta máquina recuerda al mito de Frankenstein, y su vinculación en la película con la lucha de clases (la María instigadora de la violencia y no de la paz), es sobre todo una denuncia de los riesgos de la propaganda y la rebelión de las masas.

La presencia en el cartel del Bottlik del mito de Atlas posibilita otra lectura más del mito, que se basa en los mismos valores heroico-trágicos que la figura, más explícita en Metrópolis, de Prometeo. Dicha premisa del mito como mediador sufriente, que encarna simbólicamente el cartel de Batman, permite otras dos posibilidades de interpretación de la película de Lang: por un lado, la opción cristiana, en la que Freder se identifica con la figura mediadora de Jesucristo (Jensen, 1990, p. 69), y, por otro, las lecturas prefascistas mencionadas (Sigfrido en algunas interpretaciones de Metrópolis), en las que su figura se equipara a la de un líder mesiánico, aunque su 
mesianismo consistiera en exigir estatismo político al resto de los ciudadanos (Von Harbou, 1977, p. 61).

Son todas ellas lecturas posibles, pues no pretendían dar una visión cerrada, ideológica, como sí ocurría en el uso que de estos símbolos hicieron tanto fascismos y comunismos, como el capitalismo incipiente simbolizado por el Rockefeller Center. De hecho, por el uso complejo y abierto de estos estos mitos, Metrópolis no solo fue una película premonitoria de los grandes conflictos que alimentarían la Segunda Guerra Mundial y la Guerra Fría, sino que es todavía hoy un ejemplo de lo que denominamos obra de arte superadora de su propio contexto ideológico. Dice mucho al respecto el hecho de que el mito de Atlas insinuado en el cartel de Metrópolis, que fue entonces interpretado en clave marxista, haya inspirado el más reciente cartel de Batman como mediador.

Pensamos que buena parte de este carácter intemporal de la película tiene que ver con que el uso simbólico que hace de los mitos estudiados no fue del todo preconcebido, sino resultado de un trabajo de equipo, como ilustran las declaraciones de su propio director citadas al comienzo de la exposición de este artículo (Friedkin, 1975). Fritz Lang renegó de la conclusión ideológica de la película al principio, pero la valoró adecuadamente años después, cuando los postulados nacionalsocialistas mesiánicos eran ya algo superado.

En conclusión, mientras que la distopía que presenta Metrópolis supone una visión preventiva del final del sueño europeo que estaba a punto de suceder por culpa de las actitudes prometeicas utópicas de los regímenes totalitarios, el Rockefeller Center simbolizaba una visión, también utópica, del sueño capitalista americano en su mismo nacimiento. Un sueño que ahora parece estar en entredicho, a pesar de que, a diferencia del Prometeo de Hitler y los soviéticos, que ya son sólo piezas de museo o malos recuerdos, como es el caso de Chernóbil (fig. 4), las esculturas del Rockefeller Center siguen ocupando el lugar original simbólico para el que se crearon. La cuestión pendiente es si la obra abierta que es Metrópolis, y lo que significa de sueño europeo en constante revisión aleccionadora, sobrevivirá también a estas esculturas utópicas del Rockefeller Center. 


\section{Referencias bibliográficas}

Argullol, R. (1999). El héroe y el Único. Madrid: Taurus, 1999.

Bertetto, P. (1990). Fritz Lang. Metropolis. Torino: Lindau, 1990.

Caño Diaz, H. (2018). Del objetivismo de Ayn Rand a los cómics de Steve Ditko. Perspectiva contemporánea del héroe en Estados Unidos (tesis doctoral). Universidad de Castilla-La Mancha, Toledo, España.

Dadoum, R. (1991). Metropolis: Mother-City-“Mittler”-Hitler. En Penley, C. Lyon, E. Spigel, L. Bergstrom, J. (Eds.). Close Encounters: Film, Feminism, and Science Fiction (pp. 133-161). London: University of Minnesota Press.

De Lubac, H. (1993). At the Service of the Church. San Francisco: Ignatius Press.

Devos R., Ortenberg, A. \& Paperny, V. (2015). Architecture of Great Expositions 1937-1959: Messages of Peace, Images of War. London: Ashgate.

Eco, H. (1965). Obra abierta. Barcelona: Seix barral.

Eisner, L. (1988). La pantalla demoniaca. Madrid: Cátedra.

Elsaesser, T. (2000). Metropolis. London: The British Film Institute.

Featherstone, M. (2020). Prometheus and the Degenerate: Arno Breker, Hans Bellmer, and Francis Bacon's Extreme Realism. En Lippens, R., Murray, E., Representing the Experience of War and Atrocity. Interdisciplinary Explorations in Visual Criminology (pp. 153-177). Londres: Palgrave Macmillan.

Fernandez-Vegue Olllero, D. (2017). El fuego hermenéutico: interpretaciones del mito de Prometeo (Trabajo de fin de Máster). Universidad Nacional de Educación a Distancia, Madrid, España.

Friedkin, W. (1975). Conversation with Fritz Lang, Estados Unidos: Augie Hess.

Jensen, P. (1990). Sombras en el cine de Fritz Lang. Madrid: Ediciones JC Clemente.

García Gual, C. (1979). Prometeo: mito y tragedia. Madrid: Hyperión.

Gil Olivo, R. (2005). El cine de ciencia ficción: historia e ideología. México: Centro de investigación y estudios cinematográficos.

Hinkelammert, F. (2006). Prometeo, el discernimiento de los dioses y la ética del sujeto Reflexiones sobre un mito fundante de la modernidad. Polis Revista Latinoamericana, 13, 1-27. Disponible: https://journals.openedition.org/polis/5527

Jiménez González, M. (2018). Romanticismo, técnica y poder en la arquitectura de Albert Speer. Madrid: Ápeiron ediciones. 
Jiménez González, M. (2019). Complejidad visual y narrativa en el cine de Fritz Lang en relación con el cine oscuro-expresionista alemán (tesis doctoral). Salamanca: Universidad de Salamanca.

Latorre, J. (4 de marzo de 2012). Rockefeller Center: la Atlántida global y sus símbolos [Mensaje en un blog]. Recuperado de https://imagologiajorge.wordpress.com/2012/03/04/rockefellercenter-la-altantida-global-y-sus-simbolos/

Klein, C. (1970). De los espartaquistas al nazismo: La República de Weimar. Barcelona: Ediciones Península.

Kracauer, S. (1985). De Caligari a Hitler; una historia psicológica del cine alemán. Barcelona: Paidós.

Kreimeie, K. (1999). The Ufa story: A history of germany's Greatest Film Company 1918-1945. Berkeley: University of California Press.

Marx. K. (1971). Diferencia de la filosofía de la naturaleza en Demócrito y en Epicuro, Madrid: Ayuso.

Mcgilligan, P. (2013). Fritz Lang: The nature of the beast. London: University Minnesota Press.

Overy, R. (2006). Dictadores. Barcelona: Tusquets.

Pliego Quijano, S. (2015). El hombre en la encrucijada :Diego Rivera y su mural en el Centro Rockefeller. Disponible: https://www.academia.edu/3712218/El hombre en la encrucijada _el_mural_de_Diego_Rivera_en_el_Centro_Rockefeller

Rivera, D. (1934). Portrait of America. Nueva York: Covici, Friede.

Rand, A. (2005). La rebelión de Atlas. Argentina: Editorial grito sagrado.

Safranski, R. (2009). Romanticismo. Una odisea del espíritu alemán. México: Tusquets.

Sánchez-Biosca, V. (2004). Cine y vanguardias artísticas: conflictos, encuentros, fronteras. Madrid: Paidós ibérica.

Shelley, M. (2011). Frankenstein, Madrid: Alianza.

Sudjic, D. (2010). La arquitectura del poder. Barcelona: Ariel.

Urraco Solanilla, M. y Martínez Mesa, F. (2019). Futuro poshumanos: ciencia, tecnología y transhumanismo. En Urraco Solanilla, M. y Martínez Mesa, F. De esclavos y robots y esclavas. Paisajes transmediáticos (pp. 249-281). Madrid: Los libros de la catarata.

Von Harbou, T. (1977). Metrópolis. Barcelona: ediciones Martínez Roca.

Wolfe, B. (1994). La fabulosa vida de Diego Rivera. México: Diana. 